\title{
IT Value Sustainability: Searching For Explanatory Causal Mechanisms
}

Ellen D. Hoadley, Loyola College in Maryland

\begin{abstract}
For much of the $21^{\text {st }}$ century, academics, business leaders, and practitioners have defined and measured organizational payoffs resulting from investment in information technologies (IT). This paper and presentation begin to extend the concepts of IT payoff to value sustainability. The authors synthesize the relevant literature and integrate it with the sociology concept of causal mechanisms to open up the "black box" on sustainability. A research plan is presented for review and comments.
\end{abstract}

\section{INTRODUCTION}

1 n his best-seller Good to Great, Jim Collins contends that there are specific characteristics of firms that have transformed themselves into companies that have significantly outperformed others for at least 15 years. According to Collins, these long-term performers use technology to accelerate their transformation, but they never use technology as a transformative feature in and of itself (Collins, 2001). They create sustained business value by combining appropriate technologies with well-designed processes. How does a firm that has invested in information technology (IT) sustain the value of that investment over time? What mechanisms are employed to enable sustained value from IT? What related concepts and constructs can inform our understanding of IT sustainability? This paper integrates the literature of information technology payoff, innovation for competitive advantage, knowledge management, and sociology to develop a framework to answer these important and relevant questions. The opening section discusses the current state of research in the area of IT investment value. Next, value sustainability, causal mechanisms, and absorptive capacity are explained and linked. Finally, a plan is presented for investigating absorptive capacity as a causal mechanism.

\section{VALUING THE INFORMATION TECHNOLOGY INVESTMENT}

For a number of years, executive and IT managers have struggled to determine whether or not they have extracted a sufficient return on their investments in information technology. How is the value of a firm's information technology investment measured? How does the firm identify and quantify the real returns on its IT investment? Devaraj and Kohli (2002) provide a collection of financial and operational metrics that are tools for evaluating the performance of an IT investment. They build upon the work of Hitt and Brynjolfsson (1995) in categorizing IT value as gains in productivity, profitability, and consumer surplus. The metrics incorporate various value perspectives, including the financial perspective, the customer perspective, the internal business perspective, and the innovation/learning perspective. One of the recommendations of Devaraj and Kohli (2002) is that the firms gather longitudinal data to view IT payoff and the value of the investment over a period of time rather than just at the time of implementation. This recommendation points to the need to understand the value of the IT investment as sustainable over time. 


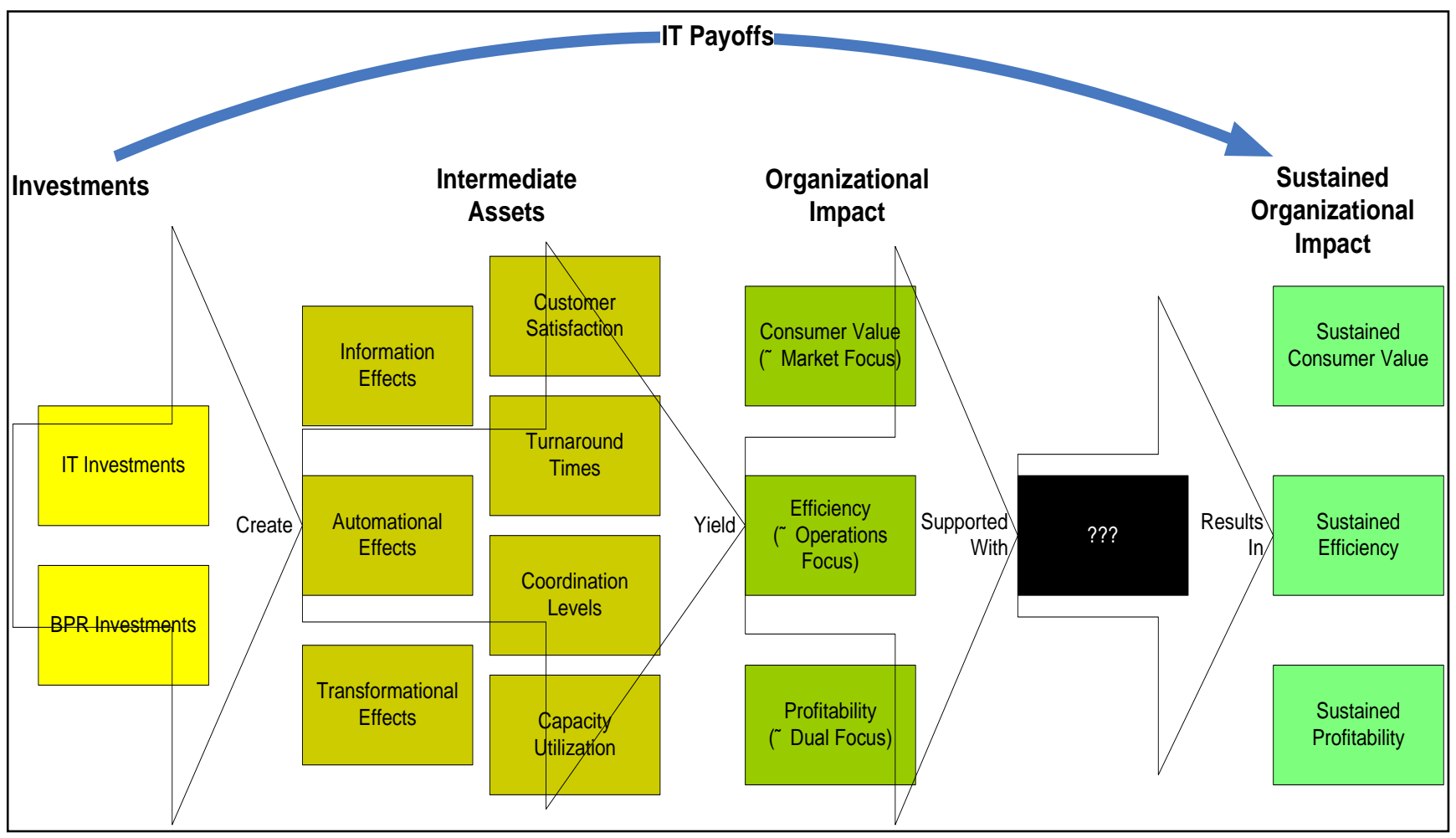

Figure 1: Expanded Model of IT Payoff Metrics (Kohli \& Hoadley, 2006)

Kohli and Hoadley (2006) validate the IT payoff metrics in three case studies in financial services, manufacturing, and healthcare. They articulate an expansive discussion on specific measures that firms use to determine whether or not their IT investment has returned value to the firm. Still, the findings of these cases do not differentiate between value of an IT investment at one point in time and a return that extends over a period of time. Figure 1 demonstrates an expansion of the Kohli and Hoadley (2006) model to incorporate this question.

Melville et al. (2004) synthesize the findings of studies on information technology and organizational performance in an integrative model. They note that the value of an information technology investment can vary based on factors within the firm and outside the firm. Their summary states that "if the right IT is applied within the right business process, improved processes and organizational performance result, conditional upon appropriate complementary investments in workplace practices and organizational structure and shaped by the competitive environment" (Melville et al., 2004, p. 292). The ongoing question is which IT investments, business processes, workplace practices, organizational structure, and competitive environment are necessary and sufficient for the improved process and organizational performance to be sustained over a period of time? Figure 2 demonstrates an expansion of the Melville et al. (2004) model to address this question. time?

So how do firms that have realized a measurable payoff from their IT investment sustain that value over 


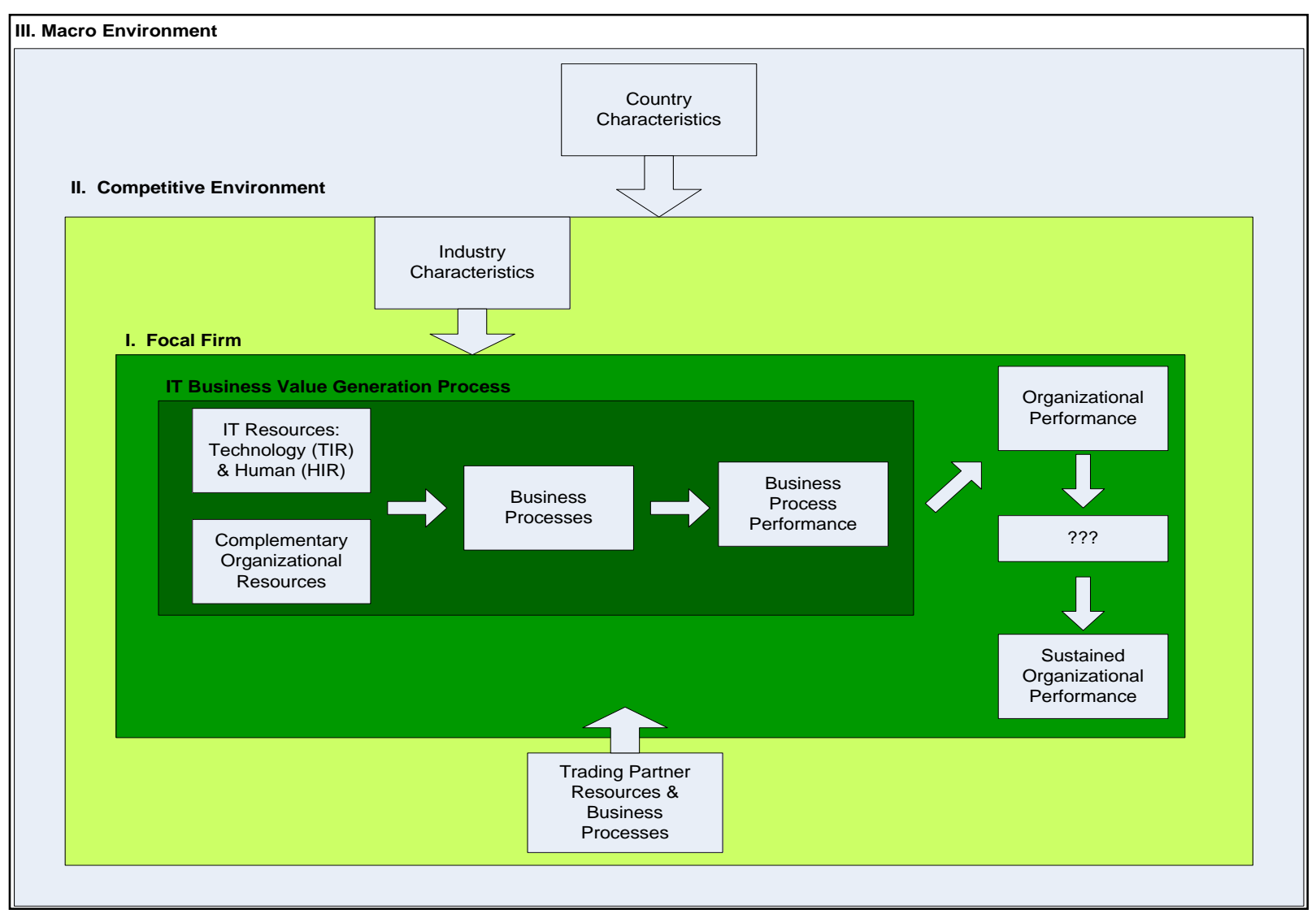

Figure 2: Expanded IT Business Value Model (Melville et al., 2004)

\section{VALUING THE IT INVESTMENT OVER TIME: SUSTAINABILITY}

The literature on IT sustainability focuses on the competitive advantage provided by developing innovative and strategic information systems. Since sustained competitive advantage results in IT value payoff in increased productivity, profitability, and consumer surplus, it logically follows that the factors of IT sustainability for value could be the same or similar to those of IT sustainability for competitive advantage. A central work in this area is that of Clemons and Row (1991) which examines sustained competitive advantage in the financial services industry. They demonstrate that sustainability is derived from linking the information systems to the complementary strategic resources of the firm. These resources may be tangible or intangible assets, but are necessary to exploit the innovation provided by the information system. Though the information system itself may be duplicated, it is the linkage to specific and unique resources of the firm that make it hard to imitate, thereby providing competitive advantage. The authors go on to expand on these strategic resources using examples from various firms in the financial services. Since the Melville et al. (2004) model includes complementary resources, perhaps it is the IT's linkage with resources that connects the concepts of competitive advantage and value sustainability.

While the studies mentioned previously about the value of an IT investment have not differentiated among types of systems investments, Dehning et al. (2003) assert that different types of systems are likely to produce different value returns. They found that IT investments that are transformative are more likely to provide positive returns than those investments that are automative or informative in nature. Then perhaps IT value sustainability is also affected by or varies based on the role that the information system fills. Therefore, in investigating the factors contributing to the sustainability of the IT payoff, this research plan will consider the strategic role and the strategic resources. 


\section{CAUSAL MECHANISMS}

If we want to uncover the factors that contribute to long-term IT value sustainability, what will have sufficient explanatory power? The constructs in the literature are widely spread and diverse, so it is important to use a unifier that will provide a comprehensive and cohesive understanding of how to accomplish IT value sustainability. The sociology literature proposes studying causal mechanisms to manipulate and explain events that occur between related constructs (Hedström and Swedberg, 2007)

Hedström and Swedberg (2007) provide a comprehensive coverage of social mechanisms as explanatory constructs that open the "black box" in events and describe what is occurring in a social or organizational event. A mechanism is a "systematic set of statements that provide a plausible account of how [an input] and [an output] are linked to one another" (Hedström \& Swedberg, 2007, p. 7). The value in a social mechanism is derived precisely from that explanatory power. It is not as general or pervasive as a theory or a law, but it is more generalizeable than the description of an event derived from a case study. For the purposes of examining IT value sustainability, determining the social mechanisms involved would be more explanatory than a case study or a collection of case studies. Mechanisms are helpful in furthering organizational theories because they provide deeper understanding that uncovers the activities and contingencies that are at work during a particular organizational event, not just whether two variables were correlated. Given that sustainability is dynamic, it requires a process approach to understanding the mechanisms that enable transitions from one state to another. Consistent with the above logic, our research plan strives to provide one or more plausible explanations of how an IT investment can provide a sustainable value to the firm.

Schelling (2007) extends the concepts of social mechanism and describes advantages of social mechanisms. First, the social mechanism provides familiar regularity to events. Second, these regularities result in activity curves, often S-curves, to describe the behavior of the social mechanism. We see many such curves in the IT literature in such areas as product life-cycles and innovation adoption and diffusion. Third, the curve that is derived can be used to explain related phenomena. The current research will seek such regularity as evidence of the existence of an explanatory social mechanism.

George and Bennett (2005) use a similar construct called causal mechanism. They propose a multi-method approach using explanatory causal mechanisms as well as observed statistical correlations to provide causal explanations of such things as IT value sustainability. They endorse case study methods because of their capabilities of process tracing and identifying causal mechanisms as well as identifying omitted variables. Case studies measure qualitative variables to provide explanations of individual cases, and of path-dependent processes, when combined with statistical correlation based methods. For simplicity, we use the term causal mechanism in this paper. Our research plan calls for one or more causal mechanisms, derived from case studies, that explain the conditions and behaviors that result in IT value sustainability.

\section{ABSORPTIVE CAPACITY AND CAUSAL MECHANISMS}

The organizational theory literature cites constructs that are candidate causal mechanisms to explain IT value sustainability. For instance, Clemons and Row (1991) list tangible resource examples as a manufacturing plant or a fleet of vehicles. Intangible resource examples include patent rights or brand image. However, what distinguishes firms that are able to link resources with sustainability may be explained by the firm's absorptive capacity, a construct proposed by the organizational memory and knowledge management literature (Cohen and Levinthal, 1990; Lane et al, 2001; Zahra and George, 2002). Absorptive capacity is defined as the set of knowledge, skills, and abilities that a firm has to manage knowledge (Zahra and George, 2002).

In the seminal article on absorptive capacity, Cohen and Levinthal (1990) examine research and development as identifiable contributors to a firm's absorptive capacity. Further, they argue that the ability to exploit any new innovation, an organization must be able to leverage its existing knowledge, skills, and abilities about the firm as well as its abilities to monitor the external environment for additional resources. This collection of knowledge, skills, and abilities of the firm comprise its absorptive capacity and are required to recognize the value 
of new ideas and information. The absorptive capacity of the firm relates to the organizational learning and knowledge transfer of the firm. Additionally, absorptive capacity requires an intensity of effort and effective communication. However, Cohen and Levinthal (1990) deal specifically with new ideas, information, technologies, or innovations. Sustainability pertains to the collection of knowledge, skills, and abilities of the firm that comprise its absorptive capacity as a requirement to sustain the value of existing ideas, information or technologies over time. Is this an extension of the absorptive capacity required for a firm to be innovative? Is it a different type of absorptive capacity? Is it something different from absorptive capacity?

Zahra and George (2002) articulate absorptive capacity as having multiple dimensions or phases. These dimensions include absorption, assimilation, transformation, and exploitation of knowledge, skills, and abilities that are brought into the firm from external sources and are useful and necessary in their operations. These phases are also candidate factors contributing to absorptive capacity as a causal mechanism. However, consistent with Cohen and Levinthal (1990) proposal, Zahra and George (2002) generalize absorptive capacity to innovation and new knowledge. We contend that sustaining the value of the firm's IT investment is similar to exploiting innovation over time. Yet the time factor has not been studied independently. The innovation in our context is an IT innovation in the form of an information system. The collective knowledge, skills, and abilities of the firm are a prerequisite to the sustaining of the value of its IT investment. Just as with innovation, IT value sustainability relates to the organizational learning and knowledge transfer of the firm, and it requires great intensity of effort. Is absorptive capacity a causal mechanism that explains all or some of the contingencies and behaviors of IT value sustainability? Figure 3 presents a visual representation of the literature linkages examined in the proposed study.

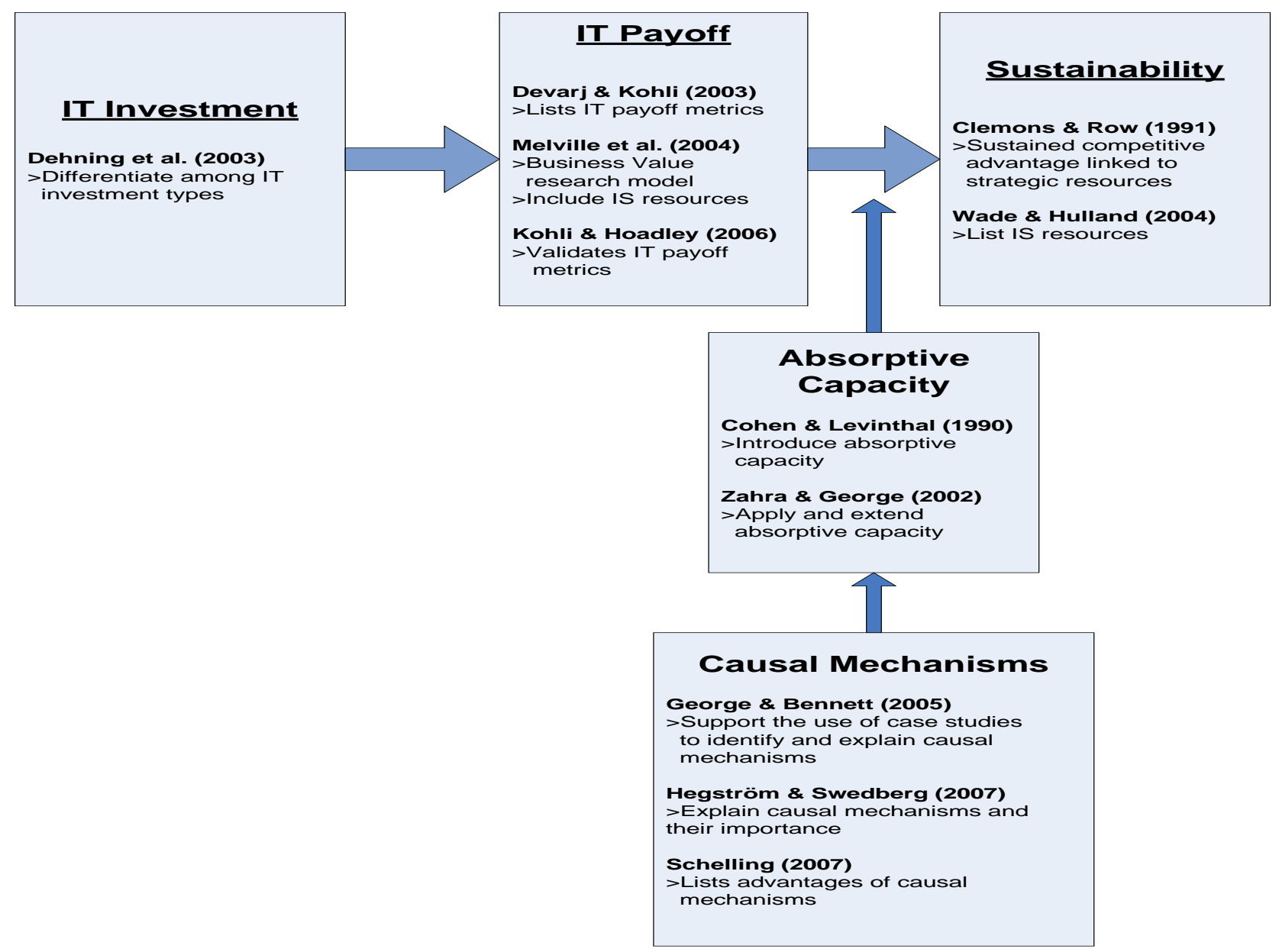

Figure 3: Conceptual Linkages in the Literature 


\section{THE PLAN TO ASSESS CAUSAL MECHANISM(S) OF IT PAYOFF SUSTAINABILITY}

The authors are presenting a research plan to answer this question. Since case studies open the "black box" of IT value sustainability, the plan incorporates multiple case studies using a Delphi technique to identify the factors that comprise the absorptive capacity of a firm as it relates to IT value sustainability. Melville et al. (2004) provide a basic set of IT business value research questions which will be expanded to address the factors of interest. Initial phase interviews will be exploratory and seek to get IT practitioners and executives to think about IT value sustainability as a concept. The questions will ask about the contingencies and behaviors that the IT practitioners identify as being relevant for IT value sustainability. The second phase will revise the questions and incorporate any of the constructs from the literature, such as the absorptive capacity dimensions, that have emerged from the original interviews.

The firms selected will be across multiple industries. Additionally, there will be a cross-section of strategic roles for the IT investments considered. After we have identified a broader set of factors that contribute to absorptive capacity a larger case study will be conducted that will provide an in-depth view of a representative firm. The goal is a closer examination and analysis of factors that contribute to absorptive capacity and how that capacity translates into IT value sustainability.

\section{CONCLUSION}

This paper has outlined a plan of research for the emerging topic of IT value sustainability. The goal is to identify the causal mechanisms that explain how organizations sustain the value of their IT investments. We believe that absorptive capacity is one of the viable mechanisms to explain the ability of firm to sustain IT value. The identification of this causal mechanism will provide the explanatory power to propose theory and provide insight to IT professionals about how to sustain the value of their IT investments.

\section{REFERENCES}

1. Clemons, E.K. and Row, M.C., Sustaining IT Advantage: the Role of Structural Differences, MIS Quarterly (15:3) Sep 1991, pp. 275-292.

2. Cohen, W. M., and Levinthal, D. A., Absorptive Capacity: A New Perspective on Learning and Innovation, Administrative Science Quarterly (35:1), Mar 1990, pp. 128-152.

3. Collins, Jim, Good to Great: Why Some Companies Make the Leap... and Others Don't, Harper Collins Publishers, Inc., New York, NY, 2001.

4. Dehning, B., Richardson, V. J., and Zmud, R. W., The Value Relevance of Announcements of Transformational Information Technology Investments, MIS Quarterly (27:4) Dec 2003, pp. 637-656.

5. Devaraj, S., and Kohli, R., The IT Payoff: Measuring the Business Value of Information Technology Investments, Prentice Hall, Inc., Upper Saddle River, NJ, 2002.

6. George, A., and Bennett, A., Case Studies and Social Science, Case Studies and Theory Development in the Social Sciences, MIT Press, Cambridge, MA, 2005, pp. 3-36.

7. Hedström, P. and Swedberg, R., Social Mechanisms: An Analytical Approach to Social Theory, Cambridge University Press, New York, NY, 2007.

8. Hitt, L., and Brynjolfsson, E., Productivity, Business Profitability, and Consumer Surplus: Three Different Measures of Information Technology Value, MIS Quarterly (20), 1995, pp. 121-142.

9. Kohli, R., and Hoadley, E. D., Towards Developing a Framework for Measuring Organizational Impact of ITEnabled BPR: Case Studies of Three Firms, The Database for Advances in Information Systems, (37:1), Winter 2006, pp. 40-58.

10. Lane, P., Salk, J. E., and Lyles, M. A., Absorptive Capacity, Learning, and Performance in International Joint Ventures, Strategic Management Journal (22:12) Dec 2001, pp. 1130-1156.

11. Melville, N., Kraemer, K., and Gurbaxani, V., Review: Information Technology and Organizational Performance: An Integrative Model of IT Business Value, MIS Quarterly, (28:2), June 2004, pp. 283-322.

12. Schelling, T.C., Social Mechanisms and Social Dynamics, Social Mechanisms: An Analytical Approach to Social Theory, Cambridge University Press, New York, NY, 2007, pp. 32-44.

13. Wade, M., and Hulland, J., Review: The Resource-Based View and Information Systems Research: Review, Extension, and Suggestions for Future Research, MIS Quarterly (28:1), March 2004, pp. 107-142.

14. Zahra, S. A., and George, G., Absorptive Capacity: A Review, Reconceptualization, and Extension, Academy of Management Review (27:2) 2002, pp. 185-203. 